\title{
EL DERECHO DE ACCIÓN EN LA CONSTITUCIÓN BRASILENA*
}

\author{
Luiz Guilherme Marinoni**
}

\begin{abstract}
RESUMEN
Este artículo trata del derecho de acción a partir de la Constitución Federal brasileña.

Propone una nueva teoría para el derecho de acción, concibiéndola como un derecho fundamental que debe estructurar el legislador infraconstitucional de modo a permitir la efectiva tutela del derecho material.

La insuficiencia de protección normativa al derecho fundamental de acción obliga al juez a reparar la falta de técnica procesal en el caso concreto, en virtud de su deber de proteger también el derecho fundamental de acción y de dar tutela jurisdiccional efectiva a toda y a cualquier situación de derecho sustancial.
\end{abstract}

\section{PALABRAS CLAVES}

Constitución, Derecho de acción como derecho fundamental, Nueva Teoría.

\begin{abstract}
This article is about the rule of action, reading by the Brazilian Federal Constitution.
\end{abstract}

* Recibido con fecha 5 de octubre y aprobada su publicación con fecha 3 de noviembre de 2007.

* Profesor Titular de la Cátedra de Derecho Procesal Civil de la Universidad Federal do Paraná - Brasil. Doctor en Derecho por la Pontificia Universidad Católica de São Paulo - Brasil. Posdoctorado en Derecho Procesal Civil en la Universidad de Milan - Italia. Autor de 16 libros (Editora Revista dos Tribunais - www.rt.com.br) y de más de una centena de artículos y de capítulos de libros. Autor del libro El derecho fundamental a la tutela jurisdiccional efectiva, Palestra Editores, Lima, 2007. Correo electrónico: guilherme@ marinoni.adv.br. - www.professormarinoni.com.br 
It proposes a new theory for the rule of action, conceiving as a fundamental right, which must be the base for the under constitution legislator to allow the material right's effective tutelage.

The insufficient legal protection of the fundamental right of rule of law obliges the judge to supply legal proceedings technique's miss in the concrete case, because your duty of provides the fundamental right of rule of law's protection and gives the effective jurisdictional tutelage for all the situations of substantial rights.

\section{KEY WORDS}

Constitution, Rule of law as a fundamental right, New theory.

\section{La historia de la garantía de acción en el derecho brasileño}

La doctrina de Marshall, cuando sintetiza que un Estado cuyas leyes no otorgan un remedio a la violación de los derechos no se le puede calificar de gobierno de leyes ${ }^{1}$, tuvo impacto en el pensamiento constitucional brasileño durante la vigencia de la primera Constitución republicana. Rui Barbosa, en el articulado que presentó ante el Supremo Tribunal Federal en 1892, manifestó que, "en donde quiera que haya un derecho individual vulnerado, habrá de haber un procedimiento judicial para la dominación de la injusticia" ${ }^{2}$. Este pensamiento, antes de ser acogido por las Constituciones brasileñas, ya había sido positivado en el art. 75 del CC de 1916, que decía " a todo derecho le corresponde una acción que lo preserve".

En las Constituciones de 1824, 1891, 1934 y 1937 no se habían formulado normas con semejante contenido. El principio de protección jurisdiccional sólo se consideró constitucional a partir de 1946. La Constitución de 1946, en su declaración de derechos y garantías individuales, declaró que "la ley no excluirá de la apreciación del Poder Judicial cualquier daño al derecho individual" (art. 141, § 4 ). El principio, consagrado en la Constitución de 1946, se repetirá en la Constitución de 1967 (art. 150, $\left.4^{\circ}\right)^{3}$ y en la Enmienda a la Constitución n. 1 de 1969 (art. $\left.153, \S 4^{\circ}\right) .^{4}$

"The very essence of civil liberty certainly consists in the right of every individual to claim the protection of the laws, whenever he receives an injury. One of the first duties of government is to afford that protection. The government of the United States has been emphatically termed a government of laws, and not of men. It will certainly cease to deserve this high appellation, if the laws furnish no remedy for the violation of a vested legal right". Marbury v. Madison, 5 U.S (1Cranch) 137 (1803) (Marshall, C.J.).

2 Rodrigues, Lêda Boechat Rodrigues, História do Supremo Tribunal Federal. Tomo I, Civilização Brasileira, Rio de Janeiro, 1991, p. 20.

Art. 150, $\S 4^{\circ}$ - A lei não poderá excluir da apreciação do Poder Judiciário qualquer lesão de direito individual. Art. $153, \S 4^{\circ}$ - A lei não poderá excluir da apreciação do Poder Judiciário qualquer lesão de direito individual. 
La Constitución de 1988 introdujo la locución "amenaza al derecho" para verbalizar dicho principio. El art. $5^{\circ}, \mathrm{XXXV}$, de la CF de 1988, afirma que "la ley no excluirá de la apreciación del Poder Judicial la lesión o la amenaza al derecho", dejando claro que la ley, además de no poder excluir la lesión, no podrá excluir la "amenaza al derecho" de la apreciación del Poder Judicial.

Asimismo, en el art. 5, XXXV, desaparecerá la alusión a "derecho individual", una constante en las Constituciones anteriores. El objetivo de esta exclusión fue resaltar que los derechos difusos y colectivos están protegidos también por la garantía de la tutela jurisdiccional efectiva.

La doctrina y los tribunales brasileños no dudan de que esta norma garantice el derecho de acción. En realidad, lo problemático está en definir la extensión de tal derecho y los ámbitos de incidencia y de protección.

\section{El derecho de acción y sus destinatarios}

\subsection{El derecho de acción en el Estado liberal}

Durante la época del Estado liberal el derecho de acción, cuando por fin se lo disocia del derecho material, se concibió como el derecho a pedirle a la Jurisdicción que realice el derecho material que le había sido negado por el obligado. Dentro de este marco, el derecho de acción, aun cuando ya había sido definido como un derecho dirigido contra el Estado, se lo veía apenas como garantía de la efectividad de las posiciones substanciales otorgadas a los ciudadanos por el Estado burgués.

El derecho de acción, en otras palabras, tenía sentido sólo como garantía de protección de la libertad, de la propiedad y, aun, para el mantenimiento del funcionamiento de los mecanismos de mercado, mediante la concesión del equivalente en dinero al acreedor que no hubiera tenido su derecho de crédito cumplido.

Durante esta época, obviamente, ni siquiera se podía pensar respecto a las dificultades económicas para el ejercicio de la acción. De la misma forma, tampoco se podía admitir la tutela específica del derecho material y, por consiguiente, vislumbrarse la necesidad de técnicas procesales adecuadas a las diferentes situaciones sustanciales carentes de tutela jurisdiccional. En realidad, las tutelas jurisdiccionales típicas de esta época, en el plano civil, eran la declarativa y la indemnizatoria por el equivalente al valor del daño o a la prestación no cumplida.

La tutela declarativa, al regular apenas formalmente una relación jurídica formada a partir de la autonomía de la voluntad, y por lo tanto no permitiendo que la fuerza del Estado incidiera sobre las relaciones privadas, hizo que la tutela jurisdiccional sea quizás más coherente con los 
valores del Estado liberal. Sin embargo, a su lado, no se podría pensar que no hubiese existido la tutela por el equivalente pecuniario, dado que el Estado no podía dejar de darle protección a aquellos que habían sufrido un daño o que tenían un derecho de crédito incumplido. Es evidente, por tanto, que su deber de protección estaba dirigido hacia la tutela de los derechos que podían transformarse en dinero, a excepción del derecho de propiedad.

Cuando el Estado concibe la transformación del derecho por equivalente pecuniario e, incluso, limita la protección jurisdiccional de la tutela por equivalente en dinero, está aceptando que los derechos y las personas son iguales o admitiendo la falta de responsabilidad con la protección específica de las diferentes posiciones sociales y de las diversas situaciones de derecho material. Admitida tal ausencia de deber de tutela, se torna natural la posibilidad de que el Estado hubiese dejado de proteger los derechos en forma específica, transformándolos por equivalente pecuniario. Se trataba, en realidad, en una forma de intentar reafirmar la igualación de los derechos y de las posiciones sociales, ahora jurisdiccionalmente.

Como no hay racionalidad en admitir procedimientos y técnicas procesales diferenciadas para derechos y posiciones sociales a los que se les debe tratar de igual forma, se elaboró un procedimiento teóricamente neutro e indiferente a la realidad. Para ello, no existía cualquier razón para que la acción se vinculase con las técnicas procesales adecuadas y capaces de permitir la efectiva tutela de las diferentes situaciones de derecho material. Era suficiente que las partes y la jurisdicción caminasen siguiendo el trazado definido por el procedimiento tipificado en la ley. El procedimiento, entendido así, era apenas una garantía de la libertad de los litigantes contra la posibilidad del arbitrio del juez, y no importaba la capacidad que tenía de permitir la efectiva tutela al derecho substancial. Incluso porque la protección jurisdiccional, en aquella época, se limitaba, por regla general, a expresar en dinero el valor de la lesión, y por lo tanto la acción y el procedimiento siempre eran adecuados.

Si el procedimiento era siempre el mismo, y no se alteraba a causa de las diferencias concretas, la acción podía ser simplemente el derecho a una decisión sobre la cuestión de fondo, con lo cual la jurisdicción sólo tenía el deber de pronunciar la sentencia.

\subsection{La prohibición para juez de negarle respuesta a la demanda de resolución de litigio}

En efecto, el concepto clásico de acción le había atribuido al Estado sólo el deber de solucionar el litigio. Desde esta perspectiva, era suficiente para garantizar el derecho de acción el antiguo principio de que el juez no se puede eximir de responder a un requerimiento de tutela jurisdiccional.

Este principio, aun cuando resultante de la negación de tutela privada y de la propia existencia de Estado, en cierta forma está presente en el CPC, que dice así, en la primera parte de su art. 126, "el juez no puede eximirse de emitir sentencia o dictar providencia alegando 
laguna u oscuridad de la ley”.

Lo cierto es que los tribunales, incluso el STF, todavía ratifican el principio de la prohibición de negación de jurisdicción, pero es más bien para dejar clara la amplitud y el contenido del deber de prestar la tutela jurisdiccional, que no puede dejar de considerar las alegaciones y las pruebas producidas por las partes ${ }^{5}$, o incluso agotarse con el pronunciamiento de la sentencia cuando, para la efectiva tutela del derecho material, se necesite la práctica de actos ejecutivos derivados de la propia fuerza estatal embutida en la sentencia de procedencia.

\subsection{La prohibición para el legislador de excluir de apreciación del Poder Judicial la lesión o la amenaza a derecho}

Otro aspecto de la visión tradicional del concepto de acción la tenemos en la prohibición de una definición legislativa de materias no jurisdiccionalizables. Es que la garantía de tutela jurisdiccional no sería tan amplia, o incluso efectiva, en caso de que el legislador especificase las materias que no se pueden debatir ante el Poder Judicial.

Las normas que están contenidas en las Constituciones brasileñas, relacionadas con la garantía de protección jurisdiccional, enunciaron siempre la prohibición de que la ley excluyera de apreciación jurisdiccional cualquier lesión a derecho individual, siendo que la Constitución de 1998, en la norma bajo comentario, se amplía el espacio de garantía de tutela jurisdiccional al adjuntarse a esta prohibición de exclusión de lesión, el veto a la exclusión de "amenaza a derecho" - sin cualificarlo como individual -, y con ello garantizarle la tutela jurisdiccional efectiva a todos los derechos - individuales, colectivos y difusos - en caso de lesión o de amenaza de lesión. ${ }^{6}$

Esta norma, si se interpreta literalmente, se dirige apenas haciael legislador, prohibiéndole un hacer, es decir, la exclusión de apreciación. La prohibición de exclusión de apreciación, así como la prohibición de que el juez se niegue a decidir, constituyen garantías de un no-hacer del Estado. Un no-hacer imprescindible para la efectividad del derecho a la tutela jurisdiccional.

\subsection{Prohibición de imposición de obstáculos para el ejercicio del derecho de acción}

Pero el legislador tampoco puede imponer óbices al ejercicio del derecho de acción, puesto que esto se configura como una exclusión de la apreciación jurisdiccional, aunque de forma

STF, Recurso Extraordinario n 172.084 (en adelante RE), $2^{\circ}$ Grupo, Rel. Min. Marco Aurélio, Diário de Justiça da União 03.03.1995 (en adelante DJU)

Ver, más adelante, apartado 3.4 . 
indirecta. A través de la imposición de obstáculos no se persigue, por regla general impedir el debate de una determinada y específica materia. Sólo afecta a determinada posición que estaría relacionada con el cumplimiento de una obligación, pero sin que esta posición pueda relacionarse con una especie de situación de derecho substancial en particular.

El STF entiende que una ley que impone el cobro de tasas judiciales excesivas para el ejercicio de la acción viola el art. $5^{\circ}, \mathrm{XXXV}$, de la CF. Con respecto al tema, la jurisprudencia de la Resolución n. 667 del STF, dice así "viola la garantía constitucional de acceso a la jurisdicción la tasa judicial calculada sin límite sobre el valor de la causa". El leading case del asunto es la Representación de Inconstitucionalidad n 1.077/RJ, de 28.03.1984, en la que el Min. Moreira Alves afirmó "tasas cuyo importe se calcula sobre el valor del beneficio o ventaja del contribuyente, como en el caso del valor real de la demanda, sobre la cual incide la alícuota invariable, necesariamente tienen que tener un límite, bajo pena de convertirse, en relación a las causas por encima de determinado valor, indiscutiblemente exorbitante en virtud del coste real de la actuación del Estado de cara al contribuyente". ${ }^{7}$

Cabe resaltar, asimismo, la prohibición de establecer una instancia administrativa obligatoria. Dicha prohibición significa que no se puede exigir el previo agotamiento de la discusión en vía administrativa para admitirse el ejercicio del derecho de acción.

En la CF de 1998 no se reproduce la segunda parte del $\S 4^{\circ}$ del art. 153 de la Constitución anterior - introducida por la EC n. 7/77 -, según la cual "la admisión en juzgado estará supeditada el previo agotamiento de las vías administrativas, desde que no se exija garantía de instancia, ni se haya ultrapasado el plazo de ciento ochenta días para la resolución de la demanda". El art. $5^{\circ}, \mathrm{XXXV}$, le prohibió a la ley crear un órgano administrativo contencioso al que se le tenga obligatoriamente que apelar o que la discusión acerca de un litigio se tenga que agotar.

Para el STF, la obligación del previo agotamiento de la vía administrativa se contrapone a la garantía de tutela jurisdiccional ${ }^{8}$. En realidad, la única excepción a la prohibición de instancia administrativa previa y obligatoria está delineada en la misma Constitución Federal, dado que, según su art. 217, $\$ 1^{\circ}$, “el Poder Judicial sólo admitirá acciones relativas a la disciplina y a las competiciones deportivas una vez agotadas las instancias de la justicia deportiva, reguladas en la ley". Sin embargo, caso las instancias de la justicia deportiva no dicten una resolución

\footnotetext{
7 (STF, Representación de Inconstitucionalidad n ${ }^{\circ}$ 1.077/RJ, Pleno, Rel.Min. Moreira Alves, DJU 28.09.1984). Ver, más adelante, STF, Pleno, Acción Directa de Inconstitucionalidad n ${ }^{\circ}$ 1.651/PB (en adelante ADI) - Medida Cautelar, Rel. Min. Sydney Sanches, DJU 11.09.1998; (en adelante MC) STF, Pleno, ADI no 1.926/PE - MC, Rel. Min. Sepúlveda Pertence, DJU 10.09.1999; STF, Pleno, ADI n 948/GO, Rel. Min. Francisco Rezek, DJU 17.03.2000.

$8 \quad$ STF, Mandamiento de Seguridad 23.789/PE (en adelante MS), Pleno, Rel. Min. Ellen Gracie, DJU 23.09.2005.
} 
final en el plazo máximo de sesenta días, contados desde la instrucción del proceso, podrá ejercer libremente el derecho de acción (art. 217, 2, $\mathrm{CF}$ ).

\subsection{El derecho de acción y su dependencia con las prestaciones estatales capaces de obstaculizar las diferencias sociales}

El derecho de acción, durante la época del Estado liberal, no se concebía como un derecho cuya realización, además de ser indispensable para la protección de los demás derechos, necesitase tomar en consideración una serie de circunstancias sociales.

En esta época de los Estados liberales, se entendía como derecho de acción sólo al derecho formal de proponer una acción. Sería parte en actuaciones judiciales quien pudiese soportar las costas de un proceso, porque la desigualdad económica y social no era objeto de preocupación del Estado. Se proclamaba el derecho de ir a juicio, pero no importaba mucho si el titular del derecho material lesionado pudiese realmente hacer usufructo de su derecho de acción. ${ }^{9}$

Sin embargo, se sabe que, desde el momento en que las libertades públicas se empezaron a ver como un privilegio de pocos, el Estado le dio una nueva apariencia y dimensión a los antiguos derechos e instituyó derechos que se pensaron como fundamentales para permitir una organización justa e igualitaria de la sociedad, y además darle oportunidad de agregarse otros contenidos al derecho de acción.

Las Constituciones del siglo XX procuraron integrar las libertades clásicas, incluso aquellas de naturaleza procesal, con los derechos sociales, para permitir la concreta participación del ciudadano en la sociedad, incluso mediante la realización del derecho de acción, que empezó a plantearse como "derecho de acceso a la justicia", transformándose en objeto de preocupación de los más modernos sistemas jurídicos. ${ }^{10}$

El derecho de acción se empieza a confrontar con un nuevo planteamiento no sólo porque se percató de que el ejercicio de la acción podría verse comprometido por obstáculos sociales y económicos, sino también porque se concientizó de que los derechos que tienen por objeto garantizar una nueva forma de sociedad, e identificados en las Constituciones modernas, sólo se concretizarían si se garantizase un real - y no un ilusorio- acceso a la justicia.

Para viabilizar el acceso a la justicia, el Estado tiene el deber de darle al autor destituido

Cappelletti, Mauro, "Los derechos sociales de libertad en la concepción de Piero Calamandrei" en Proceso, ideologías, sociedad, EJEA, Buenos Aires, 1974, p. 120 y ss.

10 Cappelletti, Mauro, "Fundamental guarantees of the parties in civil proceedings (general report)" en Fundamental guarantees of the parties in civil litigation, Giuffrè, Milano, 1973, p. 726-727. 
de condiciones financieras un abogado gratuito, así como eximirle del pago de tasas judiciales y de cualesquier costas y gastos procesales, incluso aquellas necesarias para la obtención de las pruebas.

El costo del proceso puede impedir que el ciudadano interponga la acción, aunque tenga convicción de que su derecho ha sido violado o está amenazado de violación. Esto significa que, por razones financieras, gran parte de brasileños podrían verse obligados a renunciar a sus derechos. Ahora bien, es evidente que no sirve de nada otorgar derechos y técnicas procesales adecuadas y no permitirse que el proceso pueda utilizarse por razón de obstáculos económicos.

Es por este motivo que la Constitución Federal, en su art. 5. ${ }^{\circ}$, LXXIV, afirma que "el Estado prestará asistencia jurídica integral y gratuita para quien compruebe insuficiencia de recursos". Se puede deducir que, el Estado tiene la obligación de dotarlo de un abogado a las personas menos favorecidas económicamente, y más adelante en la Constitución Federal (art. 134), se afirma también que "la Defensoría del Pueblo es una institución esencial para la función jurisdiccional del Estado, que tiene como misión la orientación jurídica y la defensa, en cualquier grado, de los necesitados, de acuerdo con lo dispuesto en el art. 5. ', LXXIV'.

Por otro lado, si el proceso es indispensable, no basta con que el Estado instituya formas de tutela si no tiene en cuenta que algunas causas pueden alcanzar un valor económico incompatible con el costo del proceso tradicional y que en determinados estratos sociales los ciudadanos tienen dificultades financieras para utilizarlo. El legislador infraconstitucional tiene la obligación - y no podría ser diferente ante la garantía constitucional del derecho de acción (art. 5. ${ }^{\circ}, \mathrm{XXXV}, \mathrm{CF}$ ) - de instituir procedimientos y justicias especializadas que permitan el acceso de los más pobres al Poder Judicial. Es necesario recordar, en este sentido, que el art. 98, I, de la CF, establece que es deber del Estado crear Juzgados Especiales para la conciliación, enjuiciamiento y ejecución de las causas civiles de "menor complejidad".

\subsection{El derecho de acción y la necesidad de una legislación infraconstitucional capaz de atribuirle efectividad}

Sin embargo el derecho de acción no depende apenas de prestaciones estatales destinadas a remover los obstáculos económicos que impidan el acceso a la justicia, sino también de prestaciones normativas instituidoras de técnicas procesales idóneas a la viabilidad de la obtención de las tutelas prometidas por el derecho substancial.

El derecho de acción no se resume simplemente al derecho a la una decisión sobre la cuestión de fondo o a una sentencia sobre la cuestión de fondo. El derecho de acción es el derecho a la efectiva y real viabilidad de la consecución de la tutela del derecho material.

Obviamente que el derecho de acción tiene como corolario el derecho a influir sobre el 
convencimiento del juez y, a su vez, el derecho a las alegaciones y a la prueba. Sin embargo, esto es prácticamente incuestionable en sede doctrinaria y jurisprudencial, y no se necesita dedicarle más atención.

Lo que realmente es importante destacar es la circunstancia de que, si las tutelas prometidas por el derecho substancial tienen diversas formas, la acción, para poder permitir la efectiva obtención de cada una de ellas, tendrá que correlacionarse con técnicas procesales adecuadas a las diferentes situaciones substanciales carentes de protección jurisdiccional. Es por ello que el derecho de acción exige la estructuración de técnicas procesales idóneas, incluyéndose aquí la técnica anticipatoria, las sentencias y los medios ejecutivos.

No obstante, el legislador no logra anticiparse a todas las necesidades de derecho material que puedan surgir, en virtud de que éstas no sólo se transforman con el paso del tiempo, sino que también asumen contornos variados conforme cada caso en concreto. Ante esto, se tomó consciencia naturalmente de la necesidad de una norma procesal destinada a darle a los justiciables y al juez el poder de identificar, aunque dentro da su ámbito, los instrumentos procesales adecuados a la tutela de los derechos.

Así, como el legislador no tiene condiciones de estructurar tantas técnicas procesales como necesidades concretas carentes de tutela, tiene el deber de sancionar normas procesales abiertas, como, por ejemplo, la del art. 461 del CPC $^{11}$. La concreción de esta norma procesal debe tener en cuenta las necesidades de derecho material reveladas en el caso en concreto, pero su institución procede, evidentemente, del derecho fundamental de acción.

Por lo tanto, el derecho de acción, si se ve desde la perspectiva de las prestaciones positivas tutela específica da obrigação ou, se procedente o pedido, determinará providências que assegurem o resultado prático equivalente ao do adimplemento.

$\S 1^{\circ}$ A obrigação somente se converterá em perdas e danos se o autor o requerer ou se impossível a tutela específica ou a obtenção do resultado prático correspondente.

$\S 2^{\circ} \mathrm{A}$ indenização por perdas e danos dar-se-á sem prejuízo da multa (art. 287).

$\S 3^{\circ}$ Sendo relevante o fundamento da demanda e havendo justificado receio de ineficácia do provimento final, é lícito ao juiz conceder a tutela liminarmente ou mediante justificação prévia, citado o réu. A medida liminar poderá ser revogada ou modificada, a qualquer tempo, em decisão fundamentada.

$\S 4^{\circ} \mathrm{O}$ juiz poderá, na hipótese do parágrafo anterior ou na sentença, impor multa diária ao réu, independentemente de pedido do autor, se for suficiente ou compatível com a obrigação, fixando-lhe prazo razoável para o cumprimento do preceito.

$\S 5^{\circ}$ Para a efetivação da tutela específica ou a obtenção do resultado prático equivalente, poderá o juiz, de ofício ou a requerimento, determinar as medidas necessárias, tais como a imposição de multa por tempo de atraso, busca e apreensão, remoção de pessoas e coisas, desfazimento de obras e impedimento de atividade nociva, se necessário com requisição de força policial.

$\S 6^{\circ} \mathrm{O}$ juiz poderá, de ofício, modificar o valor ou a periodicidade da multa, caso verifique que se tornou insuficiente ou excessiva. 
asumidas por el legislador, además de adquirir la característica de derecho de acceso a la justicia, asume la figura de derecho a la preordenación de las técnicas procesales idóneas para la viabilidad en el cumplimiento de las tutelas prometidas por el derecho substancial.

El derecho de acción, como derecho fundamental, lo debe proteger el legislador infraconstitucional, ya sea a través de prestaciones que hagan viable su acceso, o mediante prestaciones normativas instituidoras de técnicas procesales adecuadas.

\subsection{El derecho de acción y el deber judicial de dar efectiva tutela a los derechos}

Sin embargo, no basta parar en la idea de que el derecho fundamental de acción incide sobre la estructuración técnica del proceso, porque suponer que el legislador siempre atiende a las tutelas prometidas por el derecho material y a las necesidades sociales de forma adecuada constituye una ingenuidad sin excusas ${ }^{12}$.

La obligación de comprender las normas procesales a partir del derecho fundamental de acción le da al juez el poder-deber de encontrar la técnica procesal idónea a la protección del derecho material.

Como el derecho fundamental de acción incide sobre el Estado y, por consiguiente, sobre el legislador y el juez, es evidente que la omisión del legislador no justifica la omisión del juez. Si dicho derecho fundamental, para que se realice, exige que el juez esté provisto de poder suficiente para la tutela de los derechos, la ausencia de norma procesal instituidora de instrumento procesal idóneo que lo permita, constituye evidente obstáculo a la actuación de la jurisdicción y al derecho fundamental de acción. Así pues, para que la jurisdicción pueda ejercer su misión - que es tutelar los derechos - y para que el ciudadano realmente pueda tener garantizado su derecho fundamental de acción, la única alternativa es admitirle al juez la supresión de la omisión inconstitucional o de insuficiencia de protección normativa al derecho fundamental de acción.

\section{Las nuevas necesidades de tutela de los derechos y la evolución del concepto de derecho de acción}

\subsection{Efectividad de la tutela de los derechos y derecho de acción}

La transformación de la sociedad y del Estado y el consiguiente surgimiento de nuevas

\footnotetext{
12 Marinoni, Luiz Guilherme, "Il diritto alla tutela giurisdizionale effettiva nella prospettiva della teoria dei diritti fondamentali" en Studi di diritto processuale civile in onore di Giuseppe Tarzia, v. 1, Giuffrè, Milano, 2005, p. 93-162.
} 
situaciones substanciales carentes de tutela, frecuentemente de contenido no patrimonial y no raramente garantizadas como "derechos fundamentales", modificaron las razones para demandar y el propio contenido de la tutela jurisdiccional.

La jurisdicción ha dejado de tener la simple incumbencia de prestar la tutela declaratoria y la resarcitoria por su equivalente, asumiendo el deber de tutelar en forma específica los derechos, especialmente los derechos fundamentales, como el derecho fundamental del consumidor y el derecho al medio ambiente.

La prueba de ello está en la creciente atención que se le está dando a la denominada "tutela específica", prevista por el art. 461 del CPC y por el art. 84 del CDC. La tutela específica del derecho material es la protección jurisdiccional que no se limita a otorgarle al lesionado una cuantía equivalente al daño o a la obligación, sino que actúa en sentido inverso, inhibe la práctica del acto contrario al derecho o la práctica del daño o determina el resarcimiento in natura o el cumplimiento de la prestación en la forma específica o tal y como fue contratada.

No obstante, mientras la tutela prestada en dinero neutraliza la diferencia entre las varias tutelas del derecho material, admitiendo una única forma de procedimiento, la tutela específica, con una fuerte correlación con las diferentes necesidades del derecho material, requiere de formas de procedimiento diversificadas ${ }^{13}$.

Si la acción es el derecho a la viabilidad de otorgamiento de la tutela del derecho material, es evidente que tiene que tener una correlación con la forma de procedimiento idónea. Esto no significa que deben existir tantas acciones como necesidades carentes de tutela. El art. $5^{\circ}$, XXXV, de la CF, afirma el derecho de acción abstracto y atípico, pero capaz de permitir el otorgamiento de las varias tutelas prometidas por el derecho material. Es decir, el art. $5^{\circ}, \mathrm{XXXV}$, de la $\mathrm{CF}$, garantiza el derecho al procedimiento adecuado o a la técnica procesal adecuada, sin, obviamente, definir qué técnica procesal se le garantiza al justiciable.

\subsection{El derecho de acción no es apenas el derecho a pedir la resolución del litigio}

El derecho de acción no puede ser limitado al derecho a pedir la resolución de la cuestión de fondo. El derecho de acción no se agota con la interposición de la demanda inicial y la acción, por eso, no se propone simplemente, conforme se podría llegar a pensar a partir de una lectura rápida del art. 263 del $\mathrm{CPC}^{14}$.

13 Ver Marinoni, Luiz Guilherme, Técnica processual e tutela dos direitos. Ed. Revista dos Tribunais, São Paulo, 2004.

14 Art. 263. Considera-se proposta a ação, tanto que a petição inicial seja despachada pelo juiz, ou simplesmente distribuída, onde houver mais de uma vara. A propositura da ação, todavia, só produz, quanto ao réu, os efeitos mencionados no art. 219 depois que for validamente citado. 
El derecho de acción tiene diversos corolarios, se inicia con el derecho a participar adecuadamente del proceso, mediante la presentación de alegaciones y de producción de pruebas en plazo racional para influir sobre el convencimiento del juez respecto a los hechos.

Además, es incuestionable que el derecho de acción depende del procedimiento adecuado, es decir, de la preordenación de la técnica anticipatoria, de sentencias diferenciadas y de medios de ejecución diversos. En definitiva todo esto es imprescindible para que el actor pueda obtener la tutela jurisdiccional del derecho. De modo que la acción es, indudablemente, ejercida. $L a$ acción se ejerce a través del procedimiento adecuado.

\subsection{La acción no se agota con la sentencia firme}

El derecho de acción tampoco se agota con la sentencia que certifica el derecho, pero que carece de ejecución para conferirle la tutela del derecho al autor. Éste es el caso de las sentencias que dependen de ejecución, es decir, la sentencia condenatoria, el mandamiento y sentencia ejecutiva.

El pronunciamiento de estas sentencias, como se intuye, no presta la tutela del derecho. A no ser que se cumplan voluntariamente, si bien, en ese momento, pierden importancia como carentes de ejecución.

La sentencia condenatoria, a pesar de los esfuerzos doctrinarios, nunca ha prestado la tutela del derecho. Siempre ha constituido una mera fase a la prestación de la tutela jurisdiccional. Para la tutela resarcitoria por equivalente, es más importante la ejecución que la sentencia condenatoria. En otras palabras, nadie ha tenido nunca el derecho a una acción "condenatoria", admitiéndose en este caso el calificativo como el resultado deseado por el autor. Esto porque nadie ha deseado nunca la condenación, sino la tutela por equivalente al valor de la lesión o de la prestación incumplida o incluso la tutela del propio crédito pecuniario no satisfecho. De modo que si la acción puede ser calificada por la intención del autor, debe ser definida como la tutela del derecho ambicionada, y, por lo tanto, en vez de enunciarla de acción condenatoria, se debe intitular de acción resarcitoria.

Hay que subrayar, además, que la alteración del sistema ejecutivo, llevada a cabo por el CPC de 2005, ha significado algo muy importante para la teoría de la acción. La dispensa de la acción, para la ejecución de la sentencia condenatoria (art. 475, J, $\mathrm{CPC}^{15}$ ), parte de la premisa

15 Art. 475-J. Caso o devedor, condenado ao pagamento de quantia certa ou já fixada em liquidação, não o efetue no prazo de quinze dias, o montante da condenação será acrescido de multa no percentual de dez por cento e, a requerimento do credor e observado o disposto no art. 614, inciso II, desta Lei, expedir-se-á mandado de penhora e avaliação. 
de que la acción no se agota con la sentencia firme condenatoria, que exige la ejecución para que la tutela del derecho sea prestada. Más aún, se reconoce la irracionalidad cuando se usan dos acciones - una de conocimiento y otra de ejecución - para la obtención de sólo una tutela del derecho. Pues, si el derecho de acción es el derecho a la viabilidad de la obtención de la tutela del derecho material, no se puede agotar con la sentencia condenatoria, que nada más es que una técnica procesal al servicio de la efectiva prestación jurisdiccional.

\subsection{El derecho al preordenamiento de técnicas procesales adecuadas. La inconstitucionalidad de la ley que prohíbe la concesión de tutela anticipada}

Hay que traer a colación que el derecho de acción, comprendido como el derecho a la técnica procesal adecuada, no depende del reconocimiento del derecho material. El derecho de acción exige una técnica anticipatoria para la viabilidad del reconocimiento de verosimilitud del derecho invocado y del temor fundado de daño, sentencia idónea para la hipótesis de sentencia de procedencia y medio ejecutivo adecuado a ambas hipótesis. Si no está reconocido el derecho como suficiente para concedérsele la anticipación de la tutela o para la tutela final, no se podrá pensar en tales técnicas procesales.

La norma del art. $5^{\circ}, \mathrm{XXXV}$, al contrario de las normas constitucionales anteriores que garantizaban el derecho de acción, afirma que la ley, además de no poder excluir la lesión, está prohibida de excluir la "amenaza de lesión" de la apreciación jurisdiccional. El objetivo del art. $5^{\circ}, \mathrm{XXXV}$, en este asunto, ha sido dejar expreso que el derecho de acción debe propiciar la tutela inhibitoria y tener a su disposición técnicas procesales capaces de permitir la antelación de la tutela.

Hay tres corrientes en el STF respecto a la interpretación de la garantía de tutela jurisdiccional en caso de "amenaza a derecho"16. En la primera, refrendada especialmente por

\footnotetext{
$\S 1^{\circ}$ Do auto de penhora e de avaliação será de imediato intimado o executado, na pessoa de seu advogado (arts. 236 e 237), ou, na falta deste, o seu representante legal, ou pessoalmente, por mandado ou pelo correio, podendo oferecer impugnação, querendo, no prazo de quinze dias.

$\S 2^{\circ}$ Caso o oficial de justiça não possa proceder à avaliação, por depender de conhecimentos especializados, o juiz, de imediato, nomeará avaliador, assinando-lhe breve prazo para a entrega do laudo.

§ 3o $\mathrm{O}$ exeqüente poderá, em seu requerimento, indicar desde logo os bens a serem penhorados.

$\S 4$ ํㅡㄹ Efetuado o pagamento parcial no prazo previsto no caput deste artigo, a multa de dez por cento incidirá sobre o restante.

§ 5Não sendo requerida a execução no prazo de seis meses, o juiz mandará arquivar os autos, sem prejuízo de seu desarquivamento a pedido da parte.

16 Sentencia, STF, Pleno, ADI n 223/DF - MC, Rel. Min. Sepúlveda Pertence, DJU 29.06.1990; STF, Pleno, ADI $n^{\circ}$ 975/DF - MC, Rel. Min. Carlos Velloso, DJU 20.06.1997; Sentencia, STF, Pleno, ADI no 295/DF - MC, Rel. Min. Marco Aurélio; DJU 22.08.1997; STF, Pleno, ADC nº 4/DF - MC, Rel. Min. Sydney Sanches, DJU 21.05.1999; STF, Pleno, ADI nº 1576/DF - MC, Rel. Min. Marco Aurélio, DJU 06.06.2003.
} 
los Ministros Celso de Mello y Carlos Velloso sustenta que la ley que veda la concesión de medidas autosatisfactivas viola el art. $5^{\circ}, \mathrm{XXXV}$, y está de forma expresa en el siguiente fragmento del voto del Min. Celso de Mello para promover la ADI 223/DF - MC: "La protección jurisdiccional inmediata, otorgada a situaciones jurídicas expuestas a daño actual o potencial, no puede ser vulnerada por acto normativo de carácter infraconstitucional que, vedando el ejercicio preliminar da tutela jurisdiccional cautelar del Estado, propicie la aniquilación del propio derecho material". ${ }^{17}$ En la segunda, que es radicalmente opuesta, se puede advertir en los votos del Min. Moreira Alves. El Ministro en la ADI n. 223/DF - MC dijo: "Al prohibirse, en ciertos casos, por interés público, la anticipación provisoria de la satisfacción del derecho material lesionado o amenazado no excluye, evidentemente, de la apreciación del Poder Judicial la lesión o amenaza a derecho, puesto que ésta se obtiene normalmente en la satisfacción definitiva que la proporciona la acción principal, y ésta sí que no se puede vedar ya que privaría al lesionado o al amenazado del socorro del Poder Judicial". ${ }^{18}$ Después, en la ADI 1.576/DF - MC, el Ministro Moreira Alves asienta que, además de la ley poder vedar la concesión de medidas autosatisfactivas, "la tutela anticipada no es instituto constitucional. Ha sido creada por la ley. Y al igual que, al principio, se creo sin ciertos límites, no hay razón para que no se pueda limitar". ${ }^{19}$ Por último, la tercera vertiente, encabezada por el Min. Sepúlveda Pertence, expone que no es correcto recusar constitucionalidad a toda y a cualquier limitación legal que otorgue medidas autosatisfactivas, y que dicha ley restrictiva se debe analizar con un criterio de razonabilidad. En la ADI n. 223/DF - MC, antes mencionada, que fue objeto de la Medida Provisional que prohibía la concesión de medidas autosatisfactivas en las acciones cautelares y en los mandamientos de seguridad que cuestionaron el Plan Económico del Gobierno Collor, el Min. Pertence termina diciendo: "la solución estará en la utilización del sistema difuso, porque, en cada caso en concreto, ninguna medida provisional podrá substraer al juez de la causa de hacer un examen de constitucionalidad, aun bajo el prisma de la razonabilidad, de las restricciones impuestas a su poder cautelar, para que, si esa restricción la entiende abusiva, o si la entiende inconstitucional, concederle la medida autosatisfactiva, suspendiendo la aplicación, en el caso en concreto, de la medida provisional, en la proporción en que, con relación a aquel caso, la juzgue inconstitucional, por considerarla abusiva". ${ }^{20}$

La postura adoptada por el Min. Moreira Alves no tiene cabida, una vez que el derecho fundamental de acción garantiza la efectiva tutela del derecho material y, en consecuencia, la técnica anticipatoria, imprescindible para permitir la anticipación de la tutela y, de esta forma, dotar de efectividad a la tutela inhibitoria - capaz de impedir la violación del derecho - y,

\footnotetext{
17 Voto del Min. Celso de Mello en la ADI n 223/DF - MC (Sentencia, STF, Pleno, Rel. Min. Sepúlveda Pertence, DJU 29.06.1990).

18 Voto del Min. Moreira Alves en la ADI nº 223/DF - MC (Sentencia, STF, Pleno, Rel. Min. Sepúlveda Pertence, DJU 29.06.1990)

19 Voto del Min. Moreira Alves en la ADI n ${ }^{\circ}$ 1576/DF - MC (STF, Pleno, Rel. Min. Marco Aurélio, DJU 06.06.2003)

20 Sentencia, STF, Pleno, ADI nº 223/DF - MC, Rel. Min. Sepúlveda Pertence, DJU 29.06.1990.
} 
asimismo, evitar la práctica del daño. En realidad, la postura del Min. Moreira Alves abarca con nitidez la superada idea de derecho de acción como derecho a una sentencia sobre la cuestión de fondo. La técnica anticipatoria es imprescindible para darle protección al derecho fundamental de acción. Su supresión o su limitación indebida, por lo tanto es flagrantemente atentatorio contra la norma del art. $5^{\circ}, \mathrm{XXXV}$.

Por otro lado, la postura del Min. Pertence no distingue derecho a la técnica anticipatoria de derecho al otorgamiento de la anticipación de la tutela. Por supuesto que no existe derecho a la anticipación de la tutela, una vez que ésta depende de la confirmación de la verosimilitud del derecho y del temor de daño para el caso en concreto, y que son presupuestos para la concesión de la tutela anticipada con base en el art. 273, I, CPC ${ }^{21}$. El Min. Pertence alega que la restricción a la concesión de la medida autosatisfactiva puede ser abusiva (y por eso considerarse la ley inconstitucional) para determinado caso en concreto y no serlo en otro. Sin embargo, como la utilización abusiva de la restricción estaría relacionada con las necesidades presentes en el caso en concreto, la eventual inconstitucionalidad de la ley dependería de la verificación de los propios presupuestos para concederse la medida autosatisfactiva o la anticipación de la tutela. Lógicamente que, cuando se verifican en profundidad los presupuestos de la medida autosatisfactiva, obviamente que no se está examinando la utilización abusiva de la restricción a la petición de medida autosatisfactiva o cotejando su concesión, sino que se analiza si la medida autosatisfactiva es necesaria para tutelar el derecho material. En esta circunstancia, si por acaso el juez se convence de que la medida autosatisfactiva no es imprescindible, la conclusión a la que se llega no será la de que la ley restrictiva es constitucional, sino que la medida autosatisfactiva no se debe conceder en virtud de las particularidades de la circunstancia concreta. Pero, para que el juez llegue a esta conclusión de que la medida autosatisfactiva no se debe conceder, tendrá necesariamente que admitir la inconstitucionalidad de la ley.

El punto clave, para solucionar esta cuestión, reside en percibir que la ley "prohíbe la propia estimación" de los presupuestos de la medida autosatisfactiva, aunque se diga, por comodidad de lenguaje, que la ley "prohíbe la concesión" de la medida autosatisfactiva . Una ley que prohíbe la estimación de los presupuestos necesarios al otorgamiento de la medida autosatisfactiva obviamente le niega al juez la posibilidad de utilizar instrumentos imprescindibles para el ejercicio adecuado del poder que le corresponde. Y, al mismo tiempo, viola el derecho fundamental a la viabilidad de dotar de efectiva tutela al derecho material. ${ }^{22}$

21 Art. 273. O juiz poderá, a requerimento da parte, antecipar, total ou parcialmente, os efeitos da tutela pretendida no pedido inicial, desde que, existindo prova inequívoca, se convença da verossimilhança da alegação e:

I - haja fundado receio de dano irreparável ou de difícil reparação; (...)

22 Marinoni, Luiz Guilherme, Derecho fundamental a la tutela jurisdiccional efectiva, Palestra Editores, Lima, 2007, p. 248-260. 
De modo que, entre las varias posturas adoptadas en el STF, la correcta es la liderada por el Min. Celso de Mello, para quien "el acceso a la jurisdicción, proclamado en la norma constitucional de garantía, significa la posibilidad de invocar de forma irrestricta la tutela jurisdiccional cognitiva, la tutela jurisdiccional ejecutiva y la tutela jurisdiccional cautelar al Estado"23

\subsection{La regla procesal abierta como medio para la efectividad del derecho de acción}

Como resulta imposible establecer tantas técnicas procesales como situaciones substanciales carentes de tutela, el legislador instituye reglas procesales abiertas, es decir, reglas que propician la utilización de técnicas procesales para cualquier situación de derecho substancial, si están presentes, en el caso en concreto, determinadas particularidades, o, todavía, reglas que le dan al enjuiciado y al juez el poder para optar por una técnica procesal adecuada a cada caso en concreto.

El art. 273 del $\mathrm{CPC}^{24}$ le da al autor y al juez el poder para utilizar la técnica anticipatoria ante todo y cualquier conflicto, desde que esté presente i) temor fundado de daño o ii) abuso de derecho de defensa, o que iii) parte de la demanda se haya convertido en incontestable durante el transcurso del proceso (art. 273, I, II e $\left.\S 6^{\circ}, \mathrm{CPC}\right)^{25}$. O sea, basta la comparecencia de uno de estos requisitos para que la tutela anticipatoria se otorgue, careciendo de importancia

Voto del Min. Celso de Mello en la ADI n 223/DF - MC (Sentencia, STF, Pleno, Rel. Min. Sepúlveda Pertence, DJU 29.06.1990). Ver, también, ADI n 975/DF - MC, de 09.12.1993, que entendió como inconstitucional la norma que prohibía la concesión de medida autosatisfactiva contra acto de la Administración Pública sin previa audiencia de su representante; ADI $\mathrm{n}^{\circ} 1.576 / \mathrm{DF}-\mathrm{MC}$, que decidió ser inconstitucional el condicionamiento a la caución para la concesión de la medida autosatisfactiva, o de cualquier otra medida de naturaleza anticipatoria, aunque la concesión tuviese como resultado el daño a la persona jurídica de derecho público.

24 Art. 273. O juiz poderá, a requerimento da parte, antecipar, total ou parcialmente, os efeitos da tutela pretendida no pedido inicial, desde que, existindo prova inequívoca, se convença da verossimilhança da alegação e:

I - haja fundado receio de dano irreparável ou de difícil reparação; ou

II - fique caracterizado o abuso de direito de defesa ou o manifesto propósito protelatório do réu.

$\S 1^{\circ} \mathrm{Na}$ decisão que antecipar a tutela, o juiz indicará, de modo claro e preciso, as razões do seu convencimento.

$\S 2^{\circ}$ Não se concederá a antecipação da tutela quando houver perigo de irreversibilidade do provimento antecipado.

$\S 3^{\circ}$ A efetivação da tutela antecipada observará, no que couber e conforme sua natureza, as normas previstas nos arts. 588, $461, \S \S 4^{\circ}$ e $5^{\circ}$, e $461-\mathrm{A}$.

$\S 4^{\circ}$ A tutela antecipada poderá ser revogada ou modificada a qualquer tempo, em decisão fundamentada.

$\S 5^{\circ}$ Concedida ou não a antecipação da tutela, prosseguirá o processo até final julgamento.

§ 60 A tutela antecipada também poderá ser concedida quando um ou mais dos pedidos cumulados, ou parcela deles, mostrar-se incontroverso.

$\S 7$ o Se o autor, a título de antecipação de tutela, requerer providência de natureza cautelar, poderá o juiz, quando presentes os respectivos pressupostos, deferir a medida cautelar em caráter incidental do processo ajuizado. 
la naturaleza material del litigio.

Por otro lado, el art. 461 del $\mathrm{CPC}^{26}$, además de admitir también la tutela anticipatoria para cualquier caso en que el autor ambicione la "tutela específica" (art. 461, § $3^{\circ}, \mathrm{CPC}$ ), admite que el juez puede, aunque de oficio, fijar multa para conminar al demandado a hacer o a no-hacer, estipulando un valor según el caso en concreto (art. 461, $\S 4^{\circ}, \mathrm{CPC}$ ). Asimismo, el $\S 5^{\circ} \mathrm{del}$ art. 461, tal vez ante la mayor demostración normativa de que el autor y el juez deben tener el poder de definir la técnica procesal de acuerdo a las necesidades del caso, afirma específicamente que, para prestar efectiva tutela, "podrá el juez, de oficio o a petición de parte, determinar las medidas necesarias, tales como sanciones pecuniarias por tiempo de retraso, busca y captura...”.

Recordemos que, hasta hace poco tiempo, la esfera jurídica de la parte sólo se podía invadir a través de los medios ejecutivos tipificados en la ley y que las medidas autosatisfactivas apenas se otorgaban en procedimientos especiales, especialmente trazados para determinadas situaciones de derecho substancial. Y esto sin hablar de la restricción, existente en el proceso civil de tipo liberal, al empleo de las sanciones como medio ejecutivo destinado a compeler la voluntad del procesado. En esta época, como se intuye, el procedimiento y, por consiguiente, la acción no se podían estructurar de acuerdo al caso en concreto. El procedimiento formalmente rígido y el principio de tipicidad de los medios ejecutivos se veían como garantías de la libertad del litigante contra la posibilidad de arbitrio del juez.

En la actualidad, sin embargo, ante la necesidad de la tutela jurisdiccional adecuada a las nuevas situaciones de derecho substancial y la toma de consciencia de que el Estado debe tutelar los derechos de forma específica, no existe otra alternativa sino la de darle mayor amplitud

Art. 461. Na ação que tenha por objeto o cumprimento de obrigação de fazer ou não fazer, o juiz concederá a tutela específica da obrigação ou, se procedente o pedido, determinará providências que assegurem o resultado prático equivalente ao do adimplemento.

$\S 1^{\circ}$ A obrigação somente se converterá em perdas e danos se o autor o requerer ou se impossível a tutela específica ou a obtenção do resultado prático correspondente.

$\S 2^{\circ} \mathrm{A}$ indenização por perdas e danos dar-se-á sem prejuízo da multa (art. 287).

$\S 3^{\circ}$ Sendo relevante o fundamento da demanda e havendo justificado receio de ineficácia do provimento final, é lícito ao juiz conceder a tutela liminarmente ou mediante justificação prévia, citado o réu. A medida liminar poderá ser revogada ou modificada, a qualquer tempo, em decisão fundamentada.

$\S 4^{\circ} \mathrm{O}$ juiz poderá, na hipótese do parágrafo anterior ou na sentença, impor multa diária ao réu, independentemente de pedido do autor, se for suficiente ou compatível com a obrigação, fixando-lhe prazo razoável para o cumprimento do preceito.

$\S 5^{\circ}$ Para a efetivação da tutela específica ou a obtenção do resultado prático equivalente, poderá o juiz, de ofício ou a requerimento, determinar as medidas necessárias, tais como a imposição de multa por tempo de atraso, busca e apreensão, remoção de pessoas e coisas, desfazimento de obras e impedimento de atividade nociva, se necessário com requisição de força policial.

$\S 6^{\circ} \mathrm{O}$ juiz poderá, de ofício, modificar o valor ou a periodicidade da multa, caso verifique que se tornou insuficiente ou excessiva. 
de poder al Juez. Pero, el poder para fijar el importe de la multa y para escoger la "medida necesaria" conforme las necesidades del caso exige, como contrapartida, el adecuado empleo de las reglas del medio judicial idóneo y de la menor restricción posible, realzándose la necesidad de que el juez fundamente bien sus decisiones, justificando la correcta observancia de estas reglas, que, en esta hipótesis, son de vital importancia para la legitimidad del ejercicio del poder jurisdiccional.

En resumen, las normas abiertas nada más son que respuestas del legislador al derecho fundamental de acción, y plantean la tesis de que el procesado tiene el derecho fundamental a construir la acción adecuada para cada caso en concreto. ${ }^{27}$

\subsection{La insuficiente protección normativa al derecho fundamental de acción}

No obstante, aunque el legislador pueda darle protección al derecho de acción a través de normas abiertas, no es posible admitir la ausencia de regla procesal para la protección del derecho fundamental de acción ni tampoco la inexistencia de técnica procesal adecuada para determinado caso en concreto.

Por ejemplo, si tomamos en cuenta la anticipación de la tutela de suma de dinero, específicamente en la concesión de alimentos indemnizatorios en acción de resarcimiento de daño. La ejecución de esta tutela debe observar, en principio, el $\S 3^{\circ}$ del art. 273, una vez que es ésta la norma que trata de la ejecución de la tutela anticipatoria. Pero, dicha norma, al hacer alusión a las normas que deben ser observadas para la ejecución de la tutela anticipatoria, se refiere a los artículos 461 y 461-A, aplicables, respectivamente, a las obligaciones de no-hacer y de hacer y a las obligaciones de entrega de cosa, y al art. 588 (actual 475-O 28 ), relativo sobre

27 Sobre la tesis del derecho a la construcción de la acción adecuada para cada caso en concreto, ver Marinoni, Luiz Guilherme, Curso de Processo Civil - Teoria Geral do Processo. v. 1, Ed. Revista dos Tribunais, São Paulo, 2007, p. 230-310,

28 CPC - Art. 475-O. A execução provisória da sentença far-se-á, no que couber, do mesmo modo que a definitiva, observadas as seguintes normas:

I - corre por iniciativa, conta e responsabilidade do exeqüente, que se obriga, se a sentença for reformada, a reparar os danos que o executado haja sofrido;

II - fica sem efeito, sobrevindo acórdão que modifique ou anule a sentença objeto da execução, restituindo-se as partes ao estado anterior e liquidados eventuais prejuízos nos mesmos autos, por arbitramento;

III - o levantamento de depósito em dinheiro e a prática de atos que importem alienação de propriedade ou dos quais possa resultar grave dano ao executado dependem de caução suficiente e idônea, arbitrada de plano pelo juiz e prestada nos próprios autos.

$\S 1$ o No caso do inciso II do caput deste artigo, se a sentença provisória for modificada ou anulada apenas em parte, somente nesta ficará sem efeito a execução.

$\S 2^{\circ}$ A caução a que se refere o inciso III do caput deste artigo poderá ser dispensada:

I - quando, nos casos de crédito de natureza alimentar ou decorrente de ato ilícito, até o limite de sessenta vezes o valor do salário-mínimo, o exeqüente demonstrar situação de necessidade;

II - nos casos de execução provisória em que penda agravo de instrumento junto ao Supremo Tribunal Federal 
todo a la ejecución de la sentencia que condena al pago de suma en dinero. Además, la norma relativa a la ejecución de la tutela anticipatoria no dice nada respecto a los medios ejecutivos que, a fin de lograr la ejecución de alimentos en materia de responsabilidad parental - como el embargo de la nómina, el abono de pensión alimenticia y la coacción personal (artículos 733 y 734, CPC $^{29}$; artículos 17 y 18, Ley 5.478/68) -, surtirían efecto para la ejecución de la tutela de los alimentos indemnizatorios.

Por lo tanto, al reconocerse el derecho a la tutela alimenticia derivada de acto ilícito, el juez no encontrará, en la norma que regula la ejecución de la tutela anticipatoria, técnica procesal idónea. En este caso, estará ante una falta de técnica procesal adecuada o de insuficiencia normativa en materia de protección del derecho fundamental de acción.

Es evidente que la omisión de la ley procesal para instituir una técnica adecuada no elimina el deber del juez prestar, al autor que tiene motivo en el caso en concreto, la tutela que se le había sido prometida por el derecho substancial. Razonar en contra seria darle a la ley procesal la posibilidad de obstaculizar el ejercicio del poder jurisdiccional o más aún admitir que el derecho a la tutela del derecho material, aunque esté garantizada por el derecho substancial y la Constitución, puede dejar de ser efectivo dependiendo del deseo o de la suerte de la legislación procesal.

Nótese que aquí, al contrario de lo que pasa en otros casos - como, por ejemplo, en el de la insuficiencia de protección del derecho al medio ambiente o del derecho al consumidor ${ }^{30}$-, la omisión es derivada de la ausencia de técnica procesal para la efectividad de cualquier tutela prometida por el derecho substancial, sea ella proveniente de derecho fundamental o no. Y esto en virtud de que la insuficiencia de protección aflige al derecho fundamental de acción, que tiene como corolario el derecho a la preordenanza de las técnicas procesales adecuadas a la prestación de toda y de cualquier tutela prometida por el derecho material.

ou ao Superior Tribunal de Justiça (art. 544), salvo quando da dispensa possa manifestamente resultar risco de grave dano, de difícil ou incerta reparação.

(...)

29 Art. 733. Na execução de sentença ou de decisão, que fixa os alimentos provisionais, o juiz mandará citar o devedor para, em 3 (três) dias, efetuar o pagamento, provar que o fez ou justificar a impossibilidade de efetuálo.

$\S 1^{\circ}$ Se o devedor não pagar, nem se escusar, o juiz decretar-lhe-á a prisão pelo prazo de 1 (um) a 3 (três) meses.

$\S 2^{\circ} \mathrm{O}$ cumprimento da pena não exime o devedor do pagamento das prestações vencidas e vincendas.

§ 3o Paga a prestação alimentícia, o juiz suspenderá o cumprimento da ordem de prisão.

Art. 734. Quando o devedor for funcionário público, militar, diretor ou gerente de empresa, bem como empregado sujeito à legislação do trabalho, o juiz mandará descontar em folha de pagamento a importância da prestação alimentícia.

Parágrafo único. A comunicação será feita à autoridade, à empresa ou ao empregador por ofício, de que constarão os nomes do credor, do devedor, a importância da prestação e o tempo de sua duração.

30 Canaris, Claus-Wilhelm, Direitos fundamentais e direito privado (traducción de Ingo Wolfgang Sarlet y Paulo Mota Pinto), Almedina, Coimbra, 2003. 


\subsection{La supresión de la insuficiencia de técnica procesal en el caso concreto}

Como el derecho fundamental de acción también incide directamente sobre el juez (ver arriba apartado 2.7), no hay duda de que la insuficiencia de protección hacia dicho derecho fundamental debe ser suplida en el caso en concreto.

Como es bien sabido, el razonamiento decisorio pasa por dos fases, mientras que la primera se relaciona con los hechos, las pruebas y el derecho material la segunda está anclada en el derecho procesal, vinculándose con las técnicas procesales adecuadas a la prestación de la legítima tutela debida al autor. En este sentido, la segunda fase del razonamiento decisorio sólo es necesaria cuando el juez, durante la primera fase del razonamiento, determina que el autor tiene derecho a la tutela del derecho que anhela obtener.

Cuando el razonamiento decisorio alcanza la segunda fase, puede que no se encuentre técnica procesal capaz de garantizarle efectividad a la tutela del derecho - concedida al autor en la primera fase. En este momento, como se puede ver, se hace evidente la insuficiencia de legislación procesal, dándole al juez el poder de que tras examinar otras situaciones substanciales debidamente protegidas por el proceso, localizar y utilizar la técnica procesal capaz de otorgarle la debida ejecución a la tutela reconocida al derecho material.

Subráyese, además, que el razonamiento decisorio, que permite encontrar la debida técnica procesal ejecutiva, también se realiza cuando se analiza una demanda de anticipación de tutela, y no sólo al final del proceso, durante el pronunciamiento de la sentencia sobre la petición de tutela final formulada por el autor. La diferencia radica sólo en la primera fase del razonamiento decisorio, que debe tener en cuenta, conforme el caso, los presupuestos específicos para otorgarse la anticipación de la tutela o para otorgarse la tutela final, que son completamente distintos, basta recordar que, en el primer caso, se dice "verosimilitud de la alegación" y temor fundado de daño. Sin embargo, en la segunda fase del razonamiento, en ambas situaciones, al partir de la premisa de que la tutela del derecho (anticipada o final) se debe conceder, estará preocupada apenas en encontrar la debida técnica ejecutiva.

\subsection{La importancia de las reglas del medio idóneo y de menor restricción posible}

Pese a que en raras hipótesis se pueda proceder al empleo de la regla de la proporcionalidad en sentido estricto, equilibrando los derechos de acción y de defensa en el caso en concreto, siempre bastará, en caso de omisión de técnica procesal idónea, aplicar las reglas de la adecuación y de necesidad.

Esto quiere decir que, si se verifica la inexistencia de técnica procesal idónea para determinada situación de derecho substancial, el juez adoptará la técnica que, con arreglo a los valores del ordenamiento jurídico, sea idónea - en el sentido de efectiva - a la tutela del 
derecho y, al mismo tiempo, que traiga la menor restricción posible al demandado.

Aunque sea obvio, se hace necesario subrayar que la menor restricción posible no es un argumento que pueda anticiparse al del medio idóneo. O mejor dicho, no hay manera de exigirle al juez el medio que traiga la menor restricción a costa de falta de idoneidad o de efectividad de la tutela del derecho material. Esto implicaría en una inversión de razonamiento dirigido a darle concreción a la tutela de los derechos. Sólo después de la definición del medio idóneo es que el juez se preocupará, en cuál de los medios idóneos traerá la menor restricción posible.

Tales reglas son suficientes cuando se parte de la premisa de que la tutela del derecho se debe al autor y, que por eso, debe ser prestada a través del medio idóneo que traiga la menor restricción posible.

\subsection{El equilibrio entre los derechos de acción y de defensa}

Es verdad que, para la efectividad del proceso, es necesario equilibrar los derechos de acción y de defensa. ${ }^{31}$ Es lo que ocurre, por ejemplo, con la anticipación de la tutela, cuando se admite la limitación del derecho de defensa a favor del derecho de acción.

Aunque sea normal afirmar que el juez, en esta situación, equilibra los derechos de acción y de defensa, la verdad es que dicho equilibrio lo hizo el legislador al instituir la regla del art. 273, I, del CPC, admitiendo la anticipación de la tutela en caso de verosimilitud de la alegación y de temor fundado de daño.

En el caso en concreto, bastará apenas que se analice la presencia de verosimilitud del derecho y del temor fundado de daño. Si están presentes los presupuestos definidos por el legislador, el juez no podrá dejar de concederle la tutela anticipatoria.

Por otro lado, cuando el derecho fundamental de acción incide directamente sobre el juez, obligándole a dar configuración al proceso ante la insuficiencia de una ley procesal, esto normalmente ocurre en virtud de una determinada situación de derecho substancial o de una tutela prometida al autor por el derecho material. Es difícil concebir un caso en el que se le obligue al juez a suplir la omisión del legislador única y exclusivamente en virtud del propio derecho fundamental de acción.

En el art. 535 del CPC se instituyeron las solicitudes de aclaración cuyo fin es permitir la corrección de la resolución viciada por oscuridad o incompatibilidad (art. 535, I) y omisión

$31 \quad$ El derecho de defensa está garantizado en el art. 5, LV, de la CF: "aos litigantes, em processo judicial ou administrativo, e aos acusados em geral são assegurados o contraditório e ampla defesa, com os meios e recursos a ela inerentes". 
$(\text { art. 535, II })^{32}$. No se establecieron para permitir la modificación substancial de la resolución. No obstante, y en razón de diversas necesidades concretas, los tribunales les imprimieron otro aspecto a las solicitudes de aclaración, y empezaron a admitirlas para modificar la resolución en los casos de error de hecho, equivocación manifiesta o error material.

Sin embargo, cuando se les atribuye a las solicitudes de aclaración efectos modificativos de la resolución, que llamaremos de efectos infractores, se admite una forma de impugnación de las resoluciones que no había sido prevista por el legislador. De modo que las solicitudes de aclaración con efectos infractores se fundan en los derechos fundamentales de acción y de defensa, siendo uno u otro, conforme el caso, el responsable de la supresión de omisión legislativa. ${ }^{33}$

Además, estas solicitudes de aclaración, tal y como las había instituido el legislador, no admitían impugnación de la parte contraria. ${ }^{34}$ Mientras tanto, desde que se empezó a admitir el carácter modificativo de las solicitudes de aclaración, el asunto acerca del derecho a su impugnación exigió un redimensionamiento. Cualquier forma de impugnación que pueda modificar una resolución debe poder responderse por la parte que ella había beneficiado y que puede verse perjudicar por la nueva resolución que va a emitirse. En caso de que las solicitudes de aclaración con efectos de corrección de elementos fácticos hayan sido aceptadas sin la correspondiente posibilidad de respuesta, se estaría violando el derecho fundamental de la parte adversa al embargante. Fue por esta razón que el STF y el STJ empezaron a exigir la intimación de la parte contraria en las solicitudes de aclaración con efectos modificativos. ${ }^{35}$

Recuérdese que los derechos de acción y de defensa se ejercen durante todo el curso del proceso, y que por eso se desdoblan en varios actos, siendo las solicitudes de aclaración con

32 Art. 535. Cabem embargos de declaração quando:

I - houver, na sentença ou no acórdão, obscuridade ou contradição;

II - for omitido ponto sobre o qual devia pronunciar-se o juiz ou tribunal.

33 En las solicitudes de aclaración con mecanismos de corrección de elementos fácticos se incrementan las posibilidades de participación del autor y del acusado, dándole mayor efectividad a los derechos de acción y de defensa. Además, como ya se sabe que los derechos de acción y de defensa se desdoblan en una serie de corolarios - de posibilidades etc. -, es más fácil entender por qué el derecho a la prueba, el derecho a alegar y el derecho a impugnar pertenecen, por identidad de motivos, al autor y al acusado.

34 El legislador le negó la posibilidad de escrito de contestación a las solicitudes de aclaración justamente porque no tendrían nor obietivo modificar la decisión embargada.

35 "Solicitudes de aclaración y solicitudes de aclaración en el recurso de agravio reglamentario y en el recurso de agravio de instrumento - Ausencia de escrito indispensable para la estimación del recurso especial-Aclaratorias con efectos modificativos - Ausencia de notificación de los embargados - Cercenamiento de defensa Acontecimiento - Precedentes. 1. 'Aunque inexista previsión legal expresa en lo que respecta a la necesidad de notificación del embargado para impugnar solicitudes de aclaración opuestas con propósito modificativo al juzgado, la jurisprudencia del Supremo Tribunal Federal se apaciguó en relación a su exigencia, bajo pena de violación del principio del contradictorio y de la amplia defensa' (EDcl en el EDcl en el EDcl en el EREsp 172.082/DF) (STJ, 1. ${ }^{a}$ T., EEDAGA 314.971, rel. Min. Luiz Fux, DJU 31.05.2004). 
efectos infractores, bien como la respuesta que ante ellos se puede presentar, apenas formas de impugnar y de alegar, o mejor, apenas formas de participar en el proceso y de convencer al Juez. ${ }^{36}$

La oportunidad de respuesta constituye el desdoblamiento de la propia admisión de las solicitudes de aclaración con efectos infractores. No obstante, lo que realmente es relevante en este momento está en la circunstancia de que, al actuar así, el Poder Judicial admite la incidencia inmediata de los derechos fundamentales de acción y de defensa, o mejor dicho, la supresión de la omisión legal a partir de estos derechos fundamentales, lo que revela, asimismo que puede pasar imperceptible, una creación judicial del procedimiento adecuado a partir de la Constitución.

\section{Conclusión}

El derecho de acción no se puede simplificar a un mero derecho a la resolución del litigio o a obtener una sentencia que juzgue la cuestión de fondo. El derecho de acción depende de las prestaciones estatales que retiren los obstáculos económicos para el acceso a la justicia, así como torna ilegítima y nula a toda y a cualquier actuación estatal capaz de obstaculizar su ejercicio.

Pero, al lado de estas consideraciones primarias, es preciso dejar claro que las formas de tutelas jurisdiccionales de los derechos, las exige y las promete el derecho material. Hablar de tutela jurisdiccional del derecho implica asumir una postura dogmática preocupada con una forma peculiar de pensar el derecho material y su relación con el derecho procesal. Hay que subrayar, en esta dimensión, que la titularidad de un derecho debe significar una posición jurídicamente protegida, y para ello son imprescindibles las formas de tutela del derecho. Cabe decir, por ejemplo, que importa más saber que hay derecho a la tutela inhibitoria y a la tutela resarcitoria en forma específica de lo que afirmar que existe derecho al medio ambiente sano. Solamente más tarde es que entrará en escena el problema de la adecuación de las técnicas procesales para la prestación de dichas tutelas.

Es imposible pensar en tutela jurisdiccional sin separar las varias formas de tutela de los derechos de las técnicas procesales que deben hacer viable su prestación. La importancia que tiene la relación entre las formas de tutela de los derechos - que se insieren en el proceso como 
pretensiones a la tutela jurisdiccional de los derechos - y el proceso reside en garantizar el derecho a la acción adecuada para la prestación de las tutelas exigidas por el derecho material.

Sin embargo, como el legislador no consigue instituir tal número de procedimientos o técnicas procesales cuanto diversidad de necesidades carentes de tutela, no le queda otra alternativa salvo editar reglas procesales abiertas, es decir, reglas que le den al autor el poder de utilizar la técnica procesal idónea a la obtención de la tutela del derecho en el caso en concreto.

El legislador actúa de este modo, por ejemplo, cuando le confiere la oportunidad de anticipación de tutela para todo y para cualquier caso conflictivo, bastando para ello que esté presente el "fumus boni iuris" y el temor fundado de daño (art. 273, I, CPC). O incluso cuando le da al autor y al juez el poder para elegir la medida ejecutiva adecuada a la situación concreta (art. 461, §5, CPC).

No obstante, como el legislador puede omitirse al instituir técnica procesal idónea o incluso al editar regla procesal abierta, es posible que se produzca ausencia u omisión de protección al derecho fundamental de acción, o quizá mejor, inexistencia de técnica procesal capaz de permitir la efectividad del ejercicio de la acción en el caso en concreto.

Esto significa que el derecho de acción, aparte de que no se satisface más con la simples idea de resolución de litigio (sentencia que juzga el fondo del asunto) y, de que depende de las técnicas procesales idóneas a la tutela del derecho material, se debe estructurar, mediante la aplicación de las reglas abiertas, conforme a las necesidades del caso en concreto, además de deber ser conformada por el juez en el caso de insuficiencia de protección al derecho fundamental de acción.

Lo que se propone es, en otras palabras, la existencia de un derecho a la construcción de la acción adecuada a la tutela del derecho y al caso en concreto, lo cual obviamente es autónomo respecto al derecho material, pero su legitimidad depende de la tutela jurisdiccional del derecho que se reivindica a través de la acción. 